\title{
The Metabolism of Free Fatty Acids and Triacylglycerols by the Fetal Liver in a Guinea Pig Model of Intrauterine Growth Retardation
}

\author{
ANN DETMER, ANTHONY M. CARTER, AND CHRIS R. THOMAS
}

Department of Physiology, University of Odense, Denmark and Department of Endocrinology and Chemical Pathology, United Medical and Dental Schools, St. Thomas' Campus, London, England

\begin{abstract}
The aim of this study was to determine whether intrauterine growth retardation (IUGR) is associated with an alteration in hepatic lipid metabolism. IUGR was induced in 25 guinea pigs by uterine artery ligation on gestational d 30. On d 62, after anesthesia, an infusion of $\left[1-{ }^{14} \mathrm{C}\right]$-palmitic acid was given. Fetuses were exposed at 15,30 , and $45 \mathrm{~min}$, and simultaneous maternal and umbilical venous blood samples were taken. Livers were divided into right lobe, right and left sublobes of the quadrate lobe, and left lobe. In control fetuses, plasma radiolipids rose in parallel with, but were about half the value of, maternal levels. In IUGR fetuses, plasma radiolipids were lower than in controls at 15 and $30 \mathrm{~min}$ but were comparable at $45 \mathrm{~min}$. Most of the radiolipid in the maternal plasma was FFA, with only $6 \%$ incorporated into triglycerides at 45 min. In control and IUGR fetal plasmas, $36-37 \%$ of the radiolipid was triglycerides by $\mathbf{4 5}$ min. Radiolabel incorporation into the right lobe was less than into the left lobe and left half of the quadrate lobe in control and IUGR fetuses. Compared with controls, radiolabel incorporation in IUGR fetuses was less in some or all liver lobes at each time point. The proportion of label associated with FFA and triglycerides did not vary with time, between lobes, or between control and IUGR fetuses. The difference in uptake between lobes reflects their blood supply, implying that most FFA is extracted during the first passage of the umbilical venous blood. Growth retardation was not associated with compromised hepatic FFA metabolism. (Pediatr Res 32: 441-446, 1992)
\end{abstract}

\section{Abbreviations}

IUGR, intrauterine growth retardation

TG, triacylglycerol

tlc, thin-layer chromatography

Asymmetric growth is seen in many neonates born small for gestational age and is a common feature of animal models of IUGR that rely upon a reduction in maternal placental blood flow (1-4). Development of the brain and cranium is favored at the expense of the appendicular skeleton and abdominal organs, notably the liver. This study was undertaken to determine

Received January 24, 1992; accepted May 14, 1992.

Correspondence and reprint requests: Anthony M. Carter, Ph.D., Department of Physiology, University of Odense, Winsl $\phi$ wparken 19, DK-5000 Odense, Denmark.

Supported by grants from the Danish Foundation for the Advancement of Medical Science, the Danish Medical Research Council, Novo's Foundation, the P. Carl Petersen Foundation, A.L. \& D. Rasmussen's Foundation and the Special Trustees for St. Thomas' Hospital. whether and to what extent this entails an alteration in hepatic lipid metabolism. Normally, FFA are taken up from the umbilical venous blood by the fetal liver and converted to TG, which then are secreted into the blood (5-7).

The guinea pig is a useful model for studies of fetal lipid metabolism. In both the guinea pig and man, fat accounts for an appreciable share of body weight at birth (10\% and $16 \%$, respectively), and fat is an important substrate in the neonatal period (8). IUGR can be induced in guinea pigs by ligating a uterine artery early in pregnancy (9). Less fat tissue is deposited in IUGR, and the concentration of TG in the liver is reduced as growth restriction becomes severe (2). Because the growth-retarded guinea pig fetus is hypoglycemic (10), it is possible that FFA are used to a greater extent in intermediary metabolism.

This study also afforded an opportunity to look for possible differences in lipid metabolism between the liver lobes during normal fetal growth and in IUGR. In the guinea pig, the entire umbilical venous return passes through the liver, but it is unevenly distributed between the liver lobes (11). This has not been taken into account in studies of TG synthesis by the fetal liver (7). It could acquire particular significance in IUGR because it has long been known that liver damage in newborn babies occurs more frequently on the right side of the liver (12).

\section{MATERIALS AND METHODS}

Twenty-five Dunkin-Hartley guinea pigs (Mфllegaard, Lille Skensved, Denmark) were mated in our animal facility, where they were kept under controlled conditions $\left(21^{\circ} \mathrm{C}, 55 \%\right.$ relative humidity, and $12 \mathrm{~h}$ light cycle) in accordance with the European Convention for the Protection of Vertebrate Animals in Research. The animals were given free access to standard guinea pig food (Altromin, Brogaarden, Denmark), autoclaved meadow hay, and water. Ascorbic acid, $\alpha$-tocopherol, and selenium (Tokosel vet., Pharmacia, Uppsala, Sweden) were added to the drinking water. Dated pregnancies were obtained by following a procedure similar to that described by Elvidge (13).

Intrauterine growth retardation was induced by ligating the uterine artery supplying one uterine horn at $30 \mathrm{~d}$ of pregnancy. The animals were premedicated with atropine (DAK, Copenhagen, Denmark; $0.05 \mathrm{mg}$ s.c.) and xylazine (Rompun vet., Bayer, Germany; $3 \mathrm{mg} / \mathrm{kg}$ intramuscularly) and anesthetized with ketamine (Ketalar, PD \& Co., Morris Plains, NJ; 50 mg/kg s.c.). The mesometrial fat pad of one uterine horn was exposed through a small abdominal incision, and the uterine artery or the uterine artery and vein embedded in it were ligated with surgical silk at the level of the cervix. Fetuses from this horn with a brain weight/liver weight ratio $>0.85$ at the time of experiment were regarded as growth retarded. Fetuses from the contralateral horn with a ratio $<0.85$ served as controls.

At $62 \mathrm{~d}$ of pregnancy, the animals were again premedicated with atropine and xylazine and anesthetized with ketamine (50 
$\mathrm{mg} / \mathrm{kg}$ intramuscularly). Catheters were inserted in a maternal carotid artery and jugular vein. $\left[1-{ }^{14} \mathrm{C}\right]$-palmitic acid bound to human serum albumin and dissolved in saline was given by i.v. infusion. A stock solution of $\left[1-{ }^{14} \mathrm{C}\right]$-palmitic acid, bound to human serum albumin, in physiologic saline solution was diluted to a concentration of $5 \mu \mathrm{Ci} / \mathrm{mL}$. The label was given by i.v. infusion at a constant rate of $\sim 5 \mathrm{~mL} / \mathrm{h}(15.4 \mathrm{~Bq} / \mathrm{min}$ per $\mathrm{g}$ maternal body $w t)$. The precise infusion rate was determined both by calibrating the pump and by weighing the syringe before and after each infusion. A known volume of the infusate was kept for subsequent analysis. The total amount of palmitic acid given was $7.4 \mathrm{nmol} / \mathrm{min}$.

After 15 min, a small incision was made in the abdomen and the uterine wall to expose the umbilical vein of one fetus. After venipuncture with a 27 -gauge needle, $\sim 2 \mathrm{~mL}$ of blood were withdrawn from the umbilical vein. Immediately after, a $2-\mathrm{mL}$ sample of maternal arterial blood was taken. The umbilical vein was tied off and the fetus removed and killed. The fetal liver was dissected out and divided into four parts: left lobe, quadrate lobe/ left sublobe, quadrate lobe/right sublobe (including the caudate lobe), and right lobe (14). Each sample was weighed and frozen immediately in liquid $\mathrm{N}_{2}$. Blood was collected in chilled test tubes containing $2 \mathrm{mg}$ EDTA and centrifuged for $10 \mathrm{~min}$. The plasma phase was pipetted off and stored with the tissue samples at $-80^{\circ} \mathrm{C}$. This procedure was repeated for the remaining fetuses at intervals of $\sim 15 \mathrm{~min}$, the infusion of isotope-labeled palmitic acid being continued throughout the experiment. After removal of the last fetus, the mother was killed and four 1-g samples were taken from the maternal liver: left lobe, quadrate lobe/left sublobe, quadrate lobe/right sublobe, and right lobe.

Plasma samples were extracted for total lipids in 3 volumes of chloroform-methanol $(2: 1, \mathrm{vol} / \mathrm{vol})$ with elution and evaporation of the subnatant. A known weight of each tissue was homogenized (Polytron, Kinematika Gmbh, Lucerne, Switzerland) with chloroform-methanol by the method of Folch et al. (15) using three washes with $0.02 \%(\mathrm{wt} / \mathrm{vol}) \mathrm{CaCl}_{2}$. Aliquots of the plasma and tissue extracts were transferred to counting vials and dried down. After the addition of scintillation fluid (Optiscint Safe, LKB, Loughborough, UK), the samples were counted for $\beta$ emission in a liquid scintillation counter (LKB Rackbeta, LKB, Turku, Finland). The concentration of $\left[1-{ }^{14} \mathrm{C}\right]$-labeled lipids in maternal and fetal plasma and the incorporation of label in the fetal liver were calculated, and the values were corrected for variations in infusion rate, as previously described (7).

The distribution of radioactivity between FFA, TG, and other lipids was determined after separation by tlc. Aliquots taken from the plasma and tissue extracts were dissolved in chloroform and applied to tlc plates together with a mixture of standards. Separation was achieved with a mixture of hexane, ether, and acetic acid (140:60:2, vol/vol). Cholesterol, FFA, TG, and cholesterol esters were identified after staining with rhodamine. The bands were cut from the plates, and the radioactivity associated with various lipids was measured in a scintillation counter. To determine the incorporation of label into phospholipids, selected samples were separated by tlc with a mixture of chloroform, methanol, water, and acetic acid (65:25:4:1, vol/vol).

Data analysis. The data analysis was performed using the Number Cruncher Statistical System (J. L. Hintze, Kaysville, UT). Changes in total activity and percentage incorporated into lipid classes with time in maternal and fetal plasma and the four lobes of the fetal liver were examined by one-way analysis of variance. Differences between liver lobes at each time point were examined by a similar procedure. Multiple comparisons were performed with Fisher's least significant difference test, using appropriately corrected probability values. Values in the text are means $\pm \mathrm{SD}$.

\section{RESULTS}

Maternal arterial pH was $7.491 \pm 0.033, \mathrm{PCO}_{2}$ was $5.46 \pm 0.28$ $\mathrm{kPa}, \mathrm{PO}_{2}$ was $15.8 \pm 4.4 \mathrm{kPa}$, mean arterial blood pressure was
$6.85 \pm 1.41 \mathrm{kPa}(51.4 \pm 10.6 \mathrm{~mm} \mathrm{Hg})$, and heart rate was 198 $\pm 11 \mathrm{bpm}$. Fetal morphometric data are shown in Table 1 . Fifteen fetuses from the ligated horn were excluded from the study because they did not exhibit asymmetric growth (brain weight/liver weight ratio $>0.85$ ). The 22 fetuses included in the study $(60 \%)$ represent a proportion similar to that observed in an analysis of the outcome of 235 unilateral artery ligations (63\%) (16).

Maternal plasma. The maternal plasma concentration of label was $23.1 \pm 4.7 \mathrm{dpm} / \mu \mathrm{L}$ at $15 \mathrm{~min}$, with significant increases to $28.3 \pm 3.7$ and $33.3 \pm 3.5 \mathrm{dpm} / \mu \mathrm{L}$ at 30 and $45 \mathrm{~min}$, respectively $\left(F_{2,49}=28.1, p<0.001\right)$. The proportion of radioactivity associated with TG at each time point was $1.4 \pm 1.1,2.9 \pm 1.3$, and $6.4 \pm 5.7 \%$, and the corresponding percentages for FFA were $88.7 \pm 2.8,86.6 \pm 2.2$, and $82.4 \pm 10.6 \%$. There was significantly more TG $\left(F_{2.49}=9.2, p<0.001\right)$ and correspondingly less FFA $\left(F_{2,49}=4.1, p<0.05\right)$ in maternal plasma at 45 min than at 15 or $30 \mathrm{~min}$. The amount of radioactivity associated with cholesterol (5.2-6.2\%) and cholesterol esters $(0.6-0.8 \%)$ did not vary significantly with time.

Fetal plasma. The concentration of label in fetal plasma rose gradually in the control group and was significantly greater at $\mathbf{4 5}$ min than at $15 \min \left(F_{5.46}=4.9, p<0.01\right)$, whereas the percentage of label incorporated into TG rose significantly from 15 to 30 min and from 30 to $45 \min \left(F_{5,46}=9.8, p<0.001\right.$; Table 2$)$. In growth-retarded fetuses, the total concentration of label $\left(F_{5,46}=\right.$ $4.9, p<0.01)$ and incorporation into TG $\left(F_{s, 46}=9.8, p<0.001\right)$ rose to significantly higher levels after $45 \mathrm{~min}$ (Table 2 ). The amount of radioactivity associated with cholesterol $(6.1-10.2 \%)$ and cholesterol esters $(2.1-5.0 \%)$ did not vary significantly with time.

Control and IUGR fetuses are compared in Figure 1. The total concentration of label in the plasma of IUGR fetuses was significantly lower than that in the corresponding controls at 15 and $30 \mathrm{~min}$, and the percentage associated with FFA was significantly smaller in IUGR fetuses at $15 \mathrm{~min}\left(F_{5,46}=4.1, p<0.01\right)$.

Fetal liver. The $\left[1-{ }^{14} \mathrm{C}\right]$-palmitic acid label was rapidly incorporated into the fetal liver (Table 3 ). The right lobe of control and IUGR fetuses always contained significantly less radioactivity than the left lobe and the left half of the quadrate lobe (for controls $F_{3.36}=26.5$ at $15 \mathrm{~min}, 15.5$ at $30 \mathrm{~min}$, and 17.7 at 45 min; for IUGR fetuses $F_{3.24}=8.8$ at $15 \mathrm{~min}, 7.7$ at $30 \mathrm{~min}$, and $F_{3,28}=18.5$ at $45 \mathrm{~min} ; p<0.001$ throughout). It also incorporated less label than the right half of the quadrate lobe in control fetuses at each time point and IUGR fetuses at $45 \mathrm{~min}$. In addition, the right half of the quadrate lobe differed significantly from the left half of the quadrate lobe and from the left lobe in control and IUGR fetuses at $15 \mathrm{~min}$ and IUGR fetuses at 45 min and from the left lobe in control and IUGR fetuses at 30 $\min ($ all $p<0.05)$.

Compared to controls, IUGR fetuses had incorporated significantly less radioactivity in the right lobe $(t=3.1, p<0.01)$ and right half of the quadrate lobe $(t=4.1, p<0.001)$ at $15 \mathrm{~min}$, in all liver lobes at $30 \mathrm{~min}$ (right lobe, $t=4.0, p<0.01$; right quadrate lobe, $t=4.1, p<0.001$; left quadrate lobe, $t=2.4, p$ $<0.05$; left lobe $t=3.4, p<0.01$ ), and in the right sublobe of the quadrate lobe at $45 \mathrm{~min}(t=3.6, p<0.01)$.

Incorporation of $\left[{ }^{14} \mathrm{C}\right]$-radioactivity by the various liver lobes into FFA, TG, cholesterol esters, and cholesterol is shown in Figure 2. There were no significant differences between liver lobes, and no variation with time, in the proportions of FFA and TG. Incorporation of label in cholesterol esters was greater in the right lobe than in the other lobes of the liver in controls at 15 and $45 \min \left(F_{3.36}=8.1\right.$ and $\left.8.3, p<0.001\right)$ and in IUGR fetuses at $30 \mathrm{~min}\left(F_{3,24}=9.6, p<0.001\right)$. The percentage of radioactivity associated with cholesterol was also greater in the right lobe of IUGR fetuses at $30 \mathrm{~min}\left(F_{3.24}=9.1, p<0.001\right)$. The proportion of label associated with cholesterol and cholesterol esters in the livers of control fetuses decreased with time $\left(F_{11,108}=7.0\right.$ and $\left.13.4, p<0.001\right)$. 
Table 1. Body, placental, and organ weights (means \pm SD) of guinea pig fetuses used to study hepatic uptake and metabolism of $\left[1-{ }^{14} \mathrm{C}\right]$-palmitic acid after normal growth or intrauterine growth restriction (IUGR)

\begin{tabular}{|c|c|c|c|c|c|c|}
\hline & \multicolumn{2}{|c|}{$15 \mathrm{~min}$} & \multicolumn{2}{|c|}{$30 \mathrm{~min}$} & \multicolumn{2}{|c|}{$45 \mathrm{~min}$} \\
\hline & $\begin{array}{l}\text { Control } \\
(n=10) \\
\end{array}$ & $\begin{array}{l}\text { IUGR } \\
(n=7)\end{array}$ & $\begin{array}{l}\text { Control } \\
(n=10)\end{array}$ & $\begin{array}{l}\text { IUGR } \\
(n=7)\end{array}$ & $\begin{array}{l}\text { Control } \\
(n=10)\end{array}$ & $\begin{array}{l}\text { IUGR } \\
(n=8) \\
\end{array}$ \\
\hline Fetal body wt (g) & $84.8 \pm 14.1$ & $44.2 \pm 15.3^{*}$ & $84.9 \pm 17.4$ & $44.9 \pm 15.7^{*}$ & $85.9 \pm 11.5$ & $47.1 \pm 15.0^{*}$ \\
\hline Placental wt (g) & $5.41 \pm 0.89$ & $4.21 \pm 1.35^{*}$ & $5.33 \pm 1.13$ & $3.59 \pm 0.67^{*}$ & $5.64 \pm 0.99$ & $3.83 \pm 1.00^{*}$ \\
\hline \multicolumn{7}{|l|}{ Liver wt (g) } \\
\hline Left lobe & $1.08 \pm 0.29$ & $0.53 \pm 0.19^{*}$ & $1.11 \pm 0.32$ & $0.60 \pm 0.16^{*}$ & $1.15 \pm 0.21$ & $0.60 \pm 0.21^{*}$ \\
\hline $\begin{array}{l}\text { Quadrate lobe left } \\
\text { sublobe }\end{array}$ & $0.75 \pm 0.21$ & $0.37 \pm 0.09^{*}$ & $0.78 \pm 0.23$ & $0.40 \pm 0.10^{*}$ & $0.76 \pm 0.15$ & $0.40 \pm 0.14^{*}$ \\
\hline $\begin{array}{l}\text { Quadrate lobe right } \\
\text { sublobe }\end{array}$ & $0.79 \pm 0.20$ & $0.39 \pm 0.12^{*}$ & $0.83 \pm 0.24$ & $0.45 \pm 0.14^{*}$ & $0.81 \pm 0.10$ & $0.40 \pm 0.14^{*}$ \\
\hline Right lobe & $1.19 \pm 0.30$ & $0.45 \pm 0.19^{*}$ & $1.28 \pm 0.37$ & $0.48 \pm 0.20^{*}$ & $1.23 \pm 0.21$ & $0.49 \pm 0.19^{*}$ \\
\hline Brain wt (g) & $2.58 \pm 0.18$ & $2.15 \pm 0.35^{*}$ & $2.61 \pm 0.21$ & $2.24 \pm 0.26^{*}$ & $2.59 \pm 0.18$ & $2.36 \pm 0.22^{*}$ \\
\hline Brain wt/liver wt & $0.68 \pm 0.14$ & $1.25 \pm 0.38^{*}$ & $0.67 \pm 0.14$ & $1.20 \pm 0.41^{*}$ & $0.63 \pm 0.09$ & $1.31 \pm 0.46^{*}$ \\
\hline
\end{tabular}

* Significant differences between control and IUGR groups at the same time point, $p<0.05$. There were no significant differences between IUGR groups or control groups at different time points.

Table 2. Fetal plasma concentrations of total label $(\mathrm{dpm} / \mu \mathrm{L}$ wet wt) and percentage of label associated with $T G$ and FFA during maternal infusion of []$\left.^{14} \mathrm{C}\right]$-palmitate (means $\left.\pm S D\right)^{*}$

\begin{tabular}{|c|c|c|c|c|c|c|}
\hline & \multicolumn{2}{|c|}{$15 \mathrm{~min}$} & \multicolumn{2}{|c|}{$30 \mathrm{~min}$} & \multicolumn{2}{|c|}{$45 \mathrm{~min}$} \\
\hline & $\begin{array}{l}\text { Control } \\
(n=10)\end{array}$ & $\begin{array}{l}\text { IUGR } \\
(n=7)\end{array}$ & $\begin{array}{l}\text { Control } \\
(n=10)\end{array}$ & $\begin{array}{l}\text { IUGR } \\
(n=7)\end{array}$ & $\begin{array}{l}\text { Control } \\
(n=10)\end{array}$ & $\begin{array}{c}\text { IUGR } \\
(n=8)\end{array}$ \\
\hline $\begin{array}{l}\text { Total label }(\mathrm{dpm} / \mu \mathrm{L}) \\
\text { TG (\% of total) } \\
\text { FFA (\% of total) }\end{array}$ & $\begin{aligned} 11.0 & \pm 3.1 \\
4.8 & \pm 4.0 \\
79.6 & \pm 11.6\end{aligned}$ & $\begin{array}{l}6.8 \pm 3.8 \dagger \\
11.6 \pm 9.6 \\
62.7 \pm 23.0 \dagger\end{array}$ & $\begin{array}{l}14.4 \pm 3.3 \\
20.9 \pm 8.9 \S \\
65.2 \pm 12.5\end{array}$ & $\begin{array}{l}10.2 \pm 5.5 \dagger \\
22.4 \pm 19.5 \\
61.4 \pm 25.0\end{array}$ & $\begin{array}{l}15.4 \pm 5.3 \ddagger \\
35.8 \pm 17.2 \ddagger \| \\
50.8 \pm 16.5 \ddagger \|\end{array}$ & $\begin{array}{l}13.9 \pm 3.5 \ddagger \\
37.1 \pm 9.9 \| \\
49.3 \pm 10.8\end{array}$ \\
\hline
\end{tabular}

* Symbols indicate significant differences between control and IUGR groups at the same time point and between IUGR or control groups at different time points, $p<0.05$.

† IUGR value different from control value.

$\ddagger$ Forty-five-min value different from 15 -min value.

$\S$ Thirty-min value different from 15 -min value.

|| Forty-five-min value different from 15 -min value.

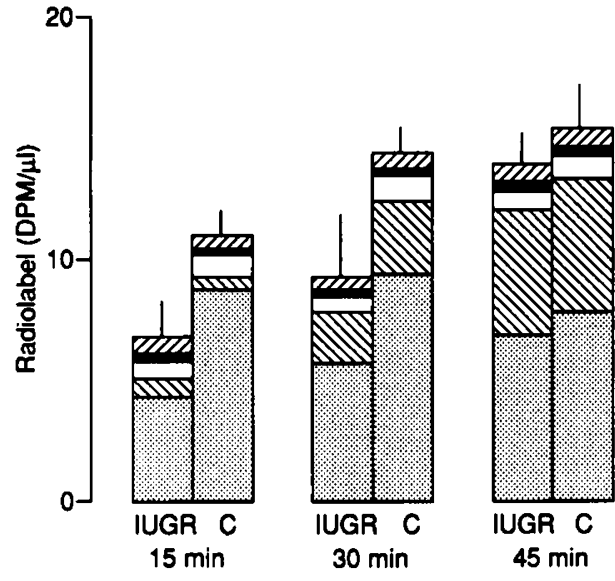

Fig. 1. Incorporation of radiolabel into the blood of growth-retarded (IUGR) and control $(C)$ fetuses at 15,30 , and 45 min during infusion of $\left[1-{ }^{14} \mathrm{C}\right]$-palmitate into a maternal vein. Shading refers to incorporation of $\left[{ }^{14} \mathrm{C}\right]$ into FFA $(\square)$, TG $(\mathbb{\mathbb { N }})$, cholesterol $(\square)$, cholesterol esters $(\square)$, and unidentified material (四). Error bars refer to total label.

Maternal liver. There were no differences between the four lobes of the maternal liver in total amount of label or in the percentage of label incorporated as FFA, TG, cholesterol esters, or cholesterol. Thus, total label in the right lobe, the right and left halves of the quadrate lobe, and the left lobe was $341 \pm 67$, $327 \pm 79,318 \pm 70$, and $310 \pm 66 \mathrm{dpm} / \mathrm{mg}$ wet weight, respectively.

Liver phospholipid incorporation. With the solvent system used to separate cholesterol, FFA, TG, and cholesterol esters, a rela- tively large fraction of the label in maternal livers $(33.2 \pm 2.7 \%)$ remained at the origin. When selected samples of maternal liver $(n=8)$ were run in an alternative solvent system to separate phospholipids, $3.5 \pm 2.3 \%$ of the label, presumably denatured lipid, was left at the origin, $24.4 \pm 1.8 \%$ migrated with phosphatidylcholine, and $5.5 \pm 0.7 \%$ migrated with phosphatidylethanolamine. Fetal livers $(n=7)$ incorporated significantly less label into phosphatidylcholine $(4.2 \pm 1.5 \%, t=23.9, p<0.001)$, with $4.2 \pm 2.2 \%$ remaining at the origin and $5.2 \pm 1.5 \%$ migrating with phosphatidylethanolamine. The amount of label that ran to the top of the plate (together with FFA, TG, palmitate esters, and cholesterol) was significantly greater in fetal than in maternal liver samples: $86.4 \pm 3.2$ and $66.5 \pm 1.8 \%$, respectively $(t=14.3$, $p<0.001$ ).

\section{DISCUSSION}

In the guinea pig, FFA is rapidly transferred from maternal to fetal blood, sequestered by the liver, and converted to TG (5-7). The results of the present study indicate important differences in FFA sequestration between the various liver lobes of both control and IUGR fetuses that can be related to differences in blood supply, supporting the view that most FFA is extracted at the first passage through the liver. Overall, transfer and assimilation of FFA did not appear to be compromised in the growthretarded fetus.

IUGR was induced by uterine artery ligation $(1,9)$. The resultant growth restriction is regarded as a model for human type II IUGR, in which body weight is affected more than length and the brain is spared at the expense of the abdominal organs (17). However, fetal growth is not always impaired by the procedure (16), and therefore we have arbitrarily defined an IUGR 
Table 3. Radioactivity in liver lobes of control and growth-retarded (IUGR) fetuses during maternal infusion of $\left[1-{ }^{14} \mathrm{C}\right]$-palmitate $(\mathrm{dpm} / \mathrm{mg} \text { wet weight; means } \pm S D)^{*}$

\begin{tabular}{|c|c|c|c|c|c|c|}
\hline & \multicolumn{2}{|c|}{$15 \mathrm{~min}$} & \multicolumn{2}{|c|}{$30 \mathrm{~min}$} & \multicolumn{2}{|c|}{$45 \mathrm{~min}$} \\
\hline & $\begin{array}{l}\text { Control } \\
(n=10)\end{array}$ & $\begin{array}{l}\text { IUGR } \\
(n=7)\end{array}$ & $\begin{array}{l}\text { Control } \\
(n=10) \\
\end{array}$ & $\begin{array}{l}\text { IUGR } \\
(n=7)\end{array}$ & $\begin{array}{l}\text { Control } \\
(n=10)\end{array}$ & $\begin{array}{l}\text { IUGR } \\
(n=8)\end{array}$ \\
\hline Right lobe & $49 \pm 27 \dagger$ & $21 \pm 9 \ddagger \S$ & $138 \pm 66 \dagger$ & $44 \pm 26 \ddagger \S$ & $148 \pm 58 \dagger$ & $126 \pm 24 \dagger$ \\
\hline $\begin{array}{l}\text { Quadrate lobe right sub- } \\
\text { lobe }\end{array}$ & $134 \pm 36 \|$ & $70 \pm 29 \ddagger \|$ & $335 \pm 129 \pi$ & $140 \pm 68 \pm \pi$ & $429 \pm 102$ & $284 \pm 70 \ddagger 1$ \\
\hline Quadrate lobe left sublobe & $167 \pm 37$ & $138 \pm 71$ & $437 \pm 119$ & $276 \pm 144 \ddagger$ & $517 \pm 160$ & $499 \pm 170$ \\
\hline Left lobe & $168 \pm 36$ & $126 \pm 58$ & $438 \pm 128$ & $236 \pm 115 \ddagger$ & $495 \pm 162$ & $430 \pm 114$ \\
\hline
\end{tabular}

* Symbols indicate significant differences between control and IUGR groups at the same time point or within-group differences between liver lobes, $p<0.05$.

† Right lobe different from other liver lobes.

$\ddagger$ IUGR value different from control value for same liver lobe.

$\S$ Right lobe different from left sublobe of quadrate lobe and left lobe.

|| Right sublobe of quadrate lobe different from left sublobe of quadrate lobe and left lobe.

I Right sublobe of quadrate lobe different from left lobe.

fetus as one with a brain weight/liver weight ratio $>0.85$. In this group of fetuses, brain weight was reduced by $13 \%$, whereas the overall decrease in liver weight was $52 \%$. In accordance with our previous findings (18), the liver lobes were unequally affected; the decrease in weight was $60 \%$ for the right lobe compared to $47 \%$ for the left lobe.

The total radioactivity in the maternal plasma increased significantly at each time point during the 45-min infusion of [1$\left.{ }^{14} \mathrm{C}\right]$-palmitate, indicating that we did not reach a steady state for radiolabeled palmitate. This was probably due to the lack of an initial bolus injection of label and the reemergence of radiolipid from fat stores in the dam during the course of the experiment. Inasmuch as unlabeled lipid was given in tracer amounts (7.4 $\mathrm{nmol} / \mathrm{min}$ ), the animals would have been in steady state for cold fat. In agreement with a previous study (7), most of the label was associated with FFA, with only modest incorporation in TG and other lipids.

Fetal plasma concentrations of the label rose gradually in control fetuses, but there was a slower rise with time in IUGR fetuses. This could be related to the lower rate of blood flow and thus of fatty acid delivery to the placentas of IUGR fetuses. However, a reduction in placental transfer capacity, analogous to that observed for $\alpha$-aminoisobutyric acid (19), cannot be excluded.

If it is assumed that the placental transfer of FFA is to a certain extent blood flow dependent, it becomes important to recognize that maternal placental blood flow is reduced by ketaminexylazine anesthesia (20). However, this effect of the anesthetic depends on a change in cardiac output rather than in placental vascular resistance and can be completely reversed by infusion of isoproterenol (20). Therefore, it is likely that any effect of the anesthetic on placental blood flow in our study would affect control and IUGR fetuses equally.

A further potential source of error is the effect of maternal blood sampling on maternal hemodynamics. We removed at most three fetuses from each dam, and cumulative maternal blood loss before removal of the third fetus was $5 \mathrm{~mL}$ or about $7 \%$ of the estimated maternal blood volume (21). Fluid replacement over the same period, including the volume of the infusate, totaled $7 \mathrm{~mL}$.

Previous studies have demonstrated a considerable concentration gradient for labeled FFA between fetal arterial blood and umbilical venous blood (6), suggesting that FFA are taken up during the first passage of the blood through the liver. This interpretation receives further support from the differences in uptake observed in this study between liver lobes (Table 3), as they can be related to differences in the blood supply of the lobes.

The ductus venosus is absent in the latter part of pregnancy in the guinea pig (22), and the entire umbilical venous return passes through the liver. It is, however, unevenly distributed between the liver lobes because the umbilical vein supplies the left lobe and the left sublobe of the quadrate lobe, whereas the right lobe and most of the right sublobe of the quadrate lobe are supplied by the portal vein. Consequently, if radioactive microspheres are injected in the umbilical vein, most are recovered from the left half of the liver (11), whereas microspheres injected in a branch of the portal vein are found almost exclusively in the right lobe and the right sublobe of the quadrate lobe (18). Therefore, if FFA are sequestered from the umbilical venous blood at the first passage through the liver, there should be greater uptake of label by the left half of the liver than by the right lobe, with the right sublobe of the quadrate lobe occupying an intermediate position. This pattern was observed in control and IUGR fetuses (Table 3). There was no difference in acquisition of label between the corresponding lobes of the maternal liver.

Differences in the blood supply to the two halves of the liver are believed to account for nonsiderotic hemilateral liver degeneration, which occurs with a frequency of $3.6 \%$ in infants that die in the perinatal period (23). The anomaly is found on the right side of the liver, in the area supplied by the portal vein, and has been ascribed to prolonged anoxia in which the oxygenation of this side of the liver becomes even more unfavorable, resulting in injury to the hepatic cells $(12,23)$.

The tendency was for less radioactivity to be incorporated by the livers of IUGR fetuses at 15 and $30 \mathrm{~min}$, but by $45 \mathrm{~min}$ these differences had largely disappeared. Once again, the slower accumulation of label probably reflects reduced fatty acid delivery to the placenta and possibly a lower placental transfer capacity for FFA. IUGR has recently been shown to be associated with a reduction in the activity of a tissue lipase within the rat placenta (24), which will affect the rate of TG hydrolysis and FFA release, thereby slowing the apparent flux through this "pool." The placentas of SGA babies have an unaltered total TG content, although the proportions of 16:0 and 18:0 fatty acids are greater in SGA placentas, with corresponding reductions in fatty acids of the linoleic acid series (25). It was recognized that these changes could lead to altered fatty acid transport to the fetal compartment, but measurements of the phosphatidylcholine fatty acid composition of cord plasma revealed little difference between small for gestational age and appropriate for gestational age babies, indicating that placental transfer of fatty acid is not greatly impaired in human IUGR (25).

Fatty liver and hyperlipemia are normal characteristics of the guinea pig fetus (26) and are in part due to the absence of lipoprotein lipase on the fetal side of the placenta (27). In the IUGR fetus, histologic examination indicates that the right lobe of the liver, which accounts for a relatively smaller proportion of liver weight, undergoes fatty degeneration (Ernst L, personal communication). Uptake of label by this lobe in IUGR fetuses was $45 \%$ or less of that in controls at 15 and $30 \mathrm{~min}$. 

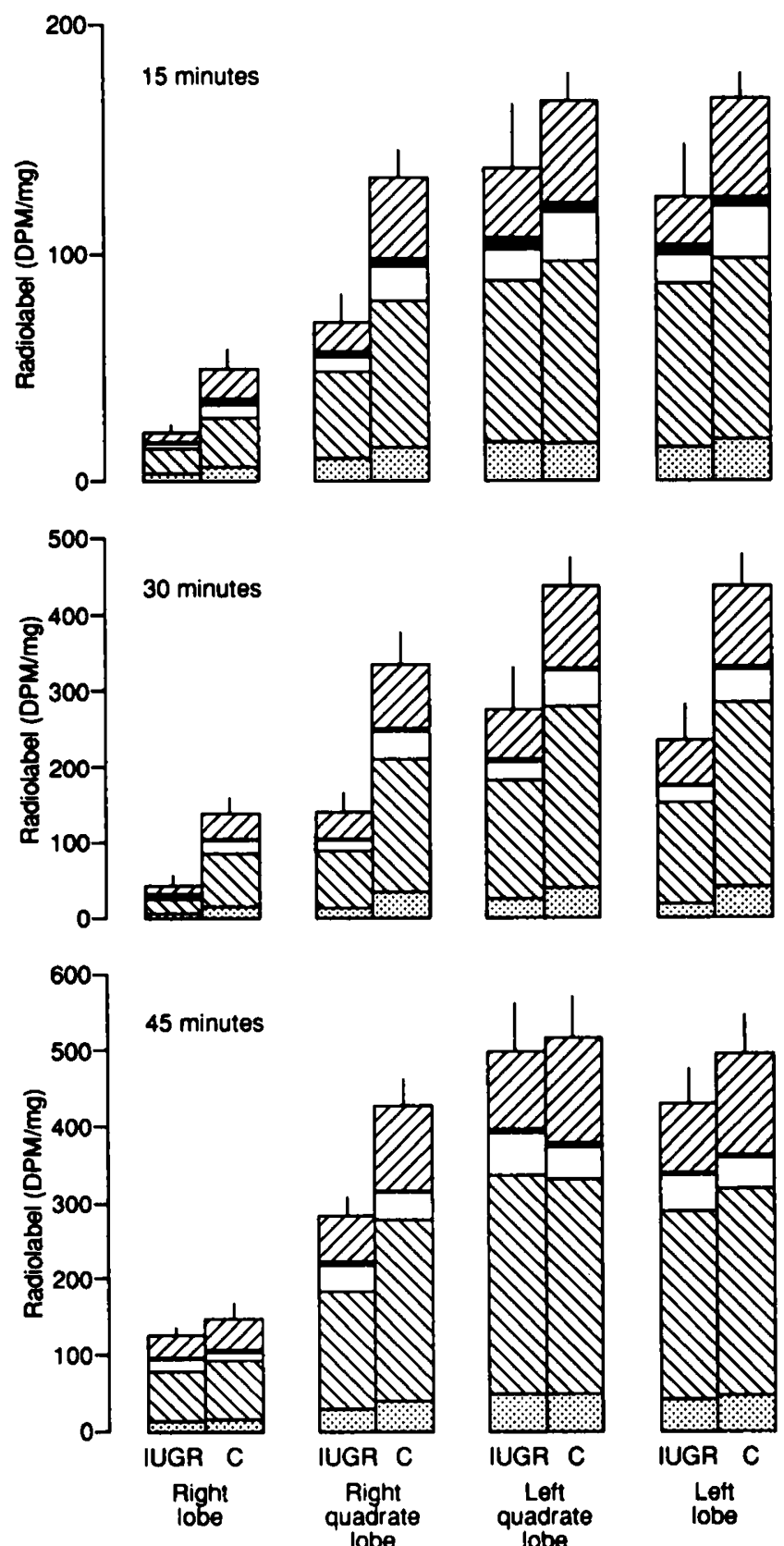

Fig. 2. Incorporation of radiolabel into the liver lobes of growthretarded $(I U G R)$ and control $(C)$ fetuses at 15,30 , and 45 min during infusion of $\left[1-{ }^{14} \mathrm{C}\right]$-palmitate into a maternal vein. Shading refers to incorporation of $\left[{ }^{14} \mathrm{C}\right]$ into FFA $(\square)$, TG $(\mathbb{\$})$, cholesterol $(\square)$, cholesterol esters (1), and unidentified material (ש). Error bars refer to total label. The liver was divided into the right lobe, right half of the quadrate lobe. left half of the quadrate lobe, and left lobe.

In the fetal liver, approximately $55 \%$ of the label was incorporated into TG. In comparable studies lasting up to $160 \mathrm{~min}$, there was a linear increase in incorporation of label into hepatic TG with time (7), but this was not seen over the shorter time course of the present experiments. The percentage of label associated with TG was similar in control and IUGR fetuses. However, in fetal plasma, incorporation into TG rose with time in control and IUGR fetuses and reached about $35 \%$ in both groups after $45 \mathrm{~min}$, a figure comparable to that previously reported (7).

In comparing IUGR with control fetuses, the reduction in size of the liver must be considered, as it is greater than the reduction in body weight. Total uptake of label and synthesis of hepatic TG was smaller in IUGR fetuses at all time points. Hepatic TG is an important fuel source for pre- and postnatal metabolism. The growth-retarded guinea pig fetus is hypoglycemic (10) and therefore may consume TG to a greater extent. The rate of fat deposition is clearly less than normal in the growth-restricted fetus and total perirenal fat is halved (2), although fat stores per $\mathrm{g}$ of body weight probably are not less at birth than in the normal fetus (2).

In conclusion, the observations of reduced FFA uptake made in this study may help to explain why total body fat is reduced in low birth weight infants (28). However, further studies on the rate of lipid turnover in IUGR fetuses are needed to enhance our understanding of this phenomenon.

\section{REFERENCES}

1. Wigglesworth JS 1964 Experimental growth retardation in the foetal rat. J Pathol Bacteriol 88:1-13

2. Lafeber HN, Rolph TP, Jones CT 1984 Studies on the growth of the fetal guinea pig. The effects of ligation of the uterine artery on organ growth and development. J Dev Physiol 6:441-459

3. Clapp JF, McLaughlin MK, Gellis J, Hemphill C, Catalano PM 1984 Regional distribution of cerebral blood flow in experimental intrauterine growth retardation. Am J Obstet Gynecol 150:843-846

4. Owens JA, Falconer J, Robinson JS 1987 Effect of restriction of placental growth on oxygen delivery to and consumption by the pregnant uterus and fetus. J Dev Physiol 9:137-150

5. Bфhmer T, Havel RJ 1975 Genesis of fatty liver and hyperlipemia in the fetal guinea pig. J Lipid Res 16:454-460

6. Jones CT 1976 Lipid metabolism and mobilization in the guinea pig during pregnancy. Biochem J 156:357-365

7. Thomas CR, Lowy C 1984 Contribution of circulating maternal lipids to fetal tissues in the guinea pig. J Dev Physiol 6:143-151

8. Thomas CR 1987 Placental transfer of non-esterified fatty acids in normal and diabetic pregnancy. Biol Neonate 51:94-101

9. Lafeber HN 1981 Experimental Intrauterine Growth Retardation in the Guinea Pig. Thesis, University of Rotterdam, pp 1-175

10. Jones CT, Harding JE, Gu W, Lafeber HN 1988 Placental metabolism and endocrine effects in relation to the control of fetal and placental growth. In: Kunzel W, Jensen A (eds) The Endocrine Control of the Fetus. SpringerVerlag, Heidelberg, Germany, pp 213-222

11. Carter AM 1984 The blood supply to the abdominal organs of the fetal guinea pig. J Dev Physiol 6:407-416

12. Gruenwald $P 1949$ Degenerative changes in the right half of the liver resulting from intra-uterine anoxia. Am J Clin Pathol 19:801-813

13. Elvidge $H 1972$ Production of dated guinea pigs without post-partum matings. J Inst Anim Tech 23:111-117

14. Cooper G, Schiller AL 1975 Anatomy of the Guinea Pig. Harvard University Press, Cambridge, MA, pp 303-324

15. Folch J, Lees M, Sloane-Stanley GH 1957 A simple method for the isolation and purification of total lipids from animal tissues. J Biol Chem 226:497509

16. Detmer A, Carter AM 1992 Factors influencing the outcome of ligating the uterine artery and vein in a guinea pig model of intrauterine growth retardation. Scand J Lab Anim Sci 19:9-16

17. Evans MI, Lin CC 1984 Retarded fetal growth. In: Lin CC, Evans MI (eds) Intrauterine Growth Retardation: Pathophysiology and Clinical Management. McGraw-Hill, New York, pp 55-77

18. Carter AM, Detmer A 1990 Blood flow to the placenta and lower body in the growth-retarded guinea pig fetus. J Dev Physiol 13:261-269

19. Jansson T, Persson E 1990 Placental transfer of glucose and amino acids in intrauterine growth retardation: studies with substrate analogs in the awake guinea pig. Pediatr Res 28:203-208

20. Myers S, Sparks JW, Makowski EL 1986 Factors affecting radioactive microsphere measurement of blood flow in pregnant guinea pigs. Lab Animal Sci 36:522-526

21. Van Dijk JP, van Kreel BK, Heeren JWA 1983 Iron metabolism and placental iron transfer in the guinea pig. J Dev Physiol 5:195-207

22. Girard H, Klappstein S, Bartag I, Moll W 1983 Blood circulation and oxygen transport in the fetal guinea pig. J Dev Physiol 5:181-193

23. Daamen CBF, Schaberg A 1969 Hemilateral liver degeneration. J Pathol 97:2934

24. Kaminsky S, D'Souza SW, Massey RF, Smart JL, Sibley CP 1991 Effects of maternal undernutrition and uterine artery ligation on placental lipase activities in the rat. Biol Neonate 60:201-206

25. Percy P. Vilbergsson G. Percy A. Mảnsson J-E, Wennergren M, Svennerholm 
L 1991 The fatty acid composition of placenta in intrauterine growth retardation. Biochim Biophys Acta 1084:173-177

26. Bфhmer T, Havel RJ, Long JA 1972 Physiological fatty liver and hyperlipemia in the fetal guinea pig: chemical and ultrastructural characterization. J Lipid Res 13:371-382

27. Thomas CR, Lowy C, St Hillaire RJ, Brunzell JD 1984 Studies on the placental hydrolysis and transfer of lipids to the fetal guinea pig. In: Miller RK, Thiede HA (eds) Fetal Nutrition, Metabolism and Immunology: Role of the Placenta. Plenum Press, New York, pp 135-148

28. Mettau JW, Degenhart HJ, Visser HKA, Holland WPS 1977 Measurement of total body fat in newborns and infants by absorption and desorption of nonradioactive xenon. Pediatr Res 11:1097-1101

\section{Announcement}

\section{New York State Nutrition Report}

Over the past 3 years, researchers at the New York State Nutrition Surveillance Program at Cornell University and the New York State Department of Health have been reviewing and summarizing nutrition data about New York State residents. The result of these efforts is a 180-page report, New York State Nurtition: State of the State. To order, send a $\$ 10.00$ check payable to Cornell University to New York State Nutrition Surveillance, Division of Nutritional Sciences, 3M4 MVR Hall, Cornell University, Ithaca, NY 14853. 